\title{
Research on the Prepositive Distance of Crosswalk Warning Markings for Unsignalized Road Section
}

\author{
Guohua Liang, Fangfang Wang $\mathbb{D}^{\mathbb{D}}$, Quan Shi, Rui Li, Zhijing Ji, and Chenchen Dong \\ School of Highway, Chang'an University, Xi'an, Shaanxi 710064, China \\ Correspondence should be addressed to Fangfang Wang; 2018121258@chd.edu.cn
}

Received 29 April 2020; Revised 25 January 2021; Accepted 31 January 2021; Published 9 February 2021

Academic Editor: Maria Vittoria Corazza

Copyright (c) 2021 Guohua Liang et al. This is an open access article distributed under the Creative Commons Attribution License, which permits unrestricted use, distribution, and reproduction in any medium, provided the original work is properly cited.

\begin{abstract}
This paper proposed an optimal prepositive distance of crosswalk warning markings for unsignalized road section under three different design speeds based on the mathematical modelling and driving simulation. To set up the most efficient mathematical modelling for calculating the layout interval of prepositive distance, the vehicles slowing down behaviour characteristics in front of crosswalk were explored. According to the layout interval, the simulation experiment was carried out in the UC-win/Road version 13.0 driving simulator. The rate of speed reduction and the times of maximum deceleration obtained from simulation experiments were selected as evaluation indicators to compare and analyse the deceleration effect related with the prepositive distances of the crosswalk warning markings under three design speeds. The results show that when the design speeds are $30 \mathrm{~km} / \mathrm{h}, 40 \mathrm{~km} / \mathrm{h}$, and $50 \mathrm{~km} / \mathrm{h}$, the optimal prepositive distances of the crosswalk warning markings are $30 \mathrm{~m}, 40 \mathrm{~m}$, and $60 \mathrm{~m}$, respectively.
\end{abstract}

\section{Introduction}

Crosswalk warning markings are widely applied on urban unsignalized road section. As the important traffic markings on urban roads, their function is to remind drivers that they are approaching the crosswalk and should slow down and pay attention to pedestrians crossing. Compared with signalized crosswalk, unsignalized crosswalk has the characteristics of low prices and low installation costs. However, due to the lack of signal lights constraints, sometimes drivers ignore the crosswalk warning markings and drive directly across the crosswalk. When pedestrians have nearly reached the lane of the located vehicle, some drivers still chose to speed up to pass through the crosswalk to save their travel time [1].

Accident statistics show that pedestrians deaths and injuries in traffic accidents account for $14 \%$ of total in the United States, $17 \%$ for Italy, and $25 \%$ for the UK, respectively $[2,3]$. On the unsignalized crosswalk, pedestrians are more likely to conflict with vehicles. The data show that $30 \%$ of pedestrian traffic accidents occur on the unsignalized crosswalk [4]. According to the statistics provided by the Ministry of Public Security, speed is one of the leading factors for the phenomenon in China [5]. Also, it has been observed that the incorrect design or management of road infrastructure can increase conflicts between pedestrians and vehicles $[6,7]$. In addition, drivers pay less attention to the road traffic signs and markings, which is another reason for this phenomenon. When cars are on road, drivers mainly focus on the information related to cars and only put about $15 \%$ of attention on the traffic signs and markings $[8,9]$. Therefore, it is significant to set road infrastructure reasonably and remind drivers to recognize the traffic information in advance and slow down.

As the important traffic markings in front of the unsignalized crosswalk, the crosswalk warning markings play an important role in reminding drivers to decelerate. In China, "Road Traffic Signs and Markings" (GB5768-2009) specified that crosswalk warning markings should be marked as white diamond pattern, longitudinal length is $3 \mathrm{~m}$, transverse length is $1.5 \mathrm{~m}$, and marking line width is $0.2 \mathrm{~m}$. The first group of crosswalk warning markings should be set between $30 \mathrm{~m}$ and $50 \mathrm{~m}$ before the crosswalk line, and the second group should be set repeatedly at intervals of $10 \mathrm{~m}$ to $20 \mathrm{~m}$ [10]. The Road Markings Manual of Japan (2004) indicates the crosswalk warning markings are usually 
set on a road section and consists of a rhombus pattern parallel to the lane line, but the rhombus pattern is not parallel patterns. New Zealand's Pedestrian Planning and Design Guide suggests that the crosswalk warning markings are marked at the centre of the lane with a width of $1 \mathrm{~m}$ and a length of $6 \mathrm{~m}$ diamond markings and placed at least $50 \mathrm{~m}$ from both sides of the crosswalk [11]. Britain drew wavy ground markings on road sections, consisting of two white $Z$ lines, to warn drivers of the presence of crosswalks ahead. It can be seen that the shape, size, and prepositive distance of the crosswalk warning markings are different in different national standards.

Currently, studies mainly concentrated on deceleration effect of traffic signs and markings. According to the research, traffic signs and markings have different effect in controlling the speed of vehicles in front of crosswalks, results show that traffic markings have more obvious effects on the deceleration of vehicles, and the speed reduction markings significantly controlled speed in practical applications $[12,13]$. In addition, scholars are beginning to study the prepositive distance of traffic signs and markings. In a study on prepositive distance of guide signs of expressway exits, results show that only the distance of the advance signs of a two-way four-lane expressway exit is close to the specified value of "Road Traffic Signs and Markings" (GB5768-2009), which is reasonable, while for expressway with six lanes and above, the specified value is small [14]. Also, another study proposed prepositive distance model and the reference of speed control signs based on the visibility distance and driving brake operate curve; meanwhile some applied design ways are also provided [15]. Driving simulation experiment is the main method to study traffic signs and markings. In a study on speed reduction markings, the author tested the effectiveness of speed reduction markings based on a driving simulation experiment and compared the difference of longitudinal speed reduction markings and transverse speed reduction markings in different conditions [16]. Chinese scholar established the scene model by virtual reality simulation technology and analysed deceleration effect of speed reduction markings through the combination of simulated driving experiment and the questionnaire survey and improved the form and parameters of four types of speed reduction markings [17]. In addition, eye trackers are also experiment equipment used in experiments, which can obtain important elements regarding the drivers' behavior during their driving activity [18].

As can be seen from the previous research, there is relatively little research about the crosswalk warning markings, especially the effectiveness of the crosswalk warning markings under certain prepositive distance at different design speeds. Therefore, the optimal prepositive distance of the crosswalk warning markings under different design speeds has become a worthy research topic. This paper took the crosswalk warning markings on urban road as the research objectives; according to the mathematical modelling and driving simulation, the optimal prepositive distance of the crosswalk warning markings is determined under the three different design speeds.

\section{Methods}

Based on the behaviour characteristics of vehicles slowing down in front of crosswalk, this paper built the mathematical modelling for calculating the layout interval of prepositive distance. Combined with the adjustment of the current regulations, the layout interval of prepositive distance is determined under design speeds of $30 \mathrm{~km} / \mathrm{h}, 40 \mathrm{~km} / \mathrm{h}$, and $50 \mathrm{~km} / \mathrm{h}$. The interval is applied into driving simulation experiment as boundary condition. The rate of speed reduction and the times of maximum deceleration obtained from simulation are used to evaluate and compare the effectiveness of deceleration and determine the optimal prepositive distance of the crosswalk warning markings under the three different design speeds.

2.1. Mathematical Modelling for Calculating Layout Interval of Prepositive Distance. In case of providing enough traffic information for drivers, usually two groups of crosswalk warning markings are required. The prepositive distance of the crosswalk warning markings should be greater than the necessary distance for slowing to stop. At the same time, considering that drivers take deceleration action after seeing the crosswalk warning markings clearly, the prepositive distance of the crosswalk warning markings should be less than the vehicle's action distance; the process of recognizing crosswalk warning markings for drivers is shown in Figure 1.

The prepositive distance of the two groups of warning markings should follow the condition of (1).

$$
M \leq L \leq D,
$$

where $D$ is the vehicle's action distance when the drivers take the deceleration action before the crosswalk warning markings; $L$ is the prepositive distance; $M$ is the shortest distance for the vehicle to decelerate and stop, where the corresponding equation (2) could be given as follows:

$$
M=\frac{v_{0}^{2}-v_{1}^{2}}{254(\varphi+\Psi)},
$$

where $v_{0}$ is the initial speed; $v_{1}$ is the speed of the vehicle after braking (take $0 \mathrm{~km} / \mathrm{h}$ ), which means the vehicle slows down to a stop; $\varphi$ is the adhesion coefficient between the road surface and the tire (the average value of the asphalt road surface under dry conditions is 0.7$)$; $\Psi$ is a coefficient of road ramp and $\Psi=f+i$, where $f$ is rolling coefficient (take it as $0.01 \sim 0.02$ for cement and asphalt concrete pavement) and $i$ is road slope [19]. This paper assumes that the vehicle is driving on a dry and level asphalt road.

The travel distance of the vehicle during its deceleration is denoted by $D$; it can be expressed as

$$
D=\sum_{1}^{3} D_{i},
$$

where $i=1,2,3, D_{1}$ is the driving distance from braking behaviour beginning to vehicle start decelerating, $D_{2}$ is the driving distance during vehicle's uniform motion, and $D_{3}$ is the distance that the vehicle decelerates to stop. 


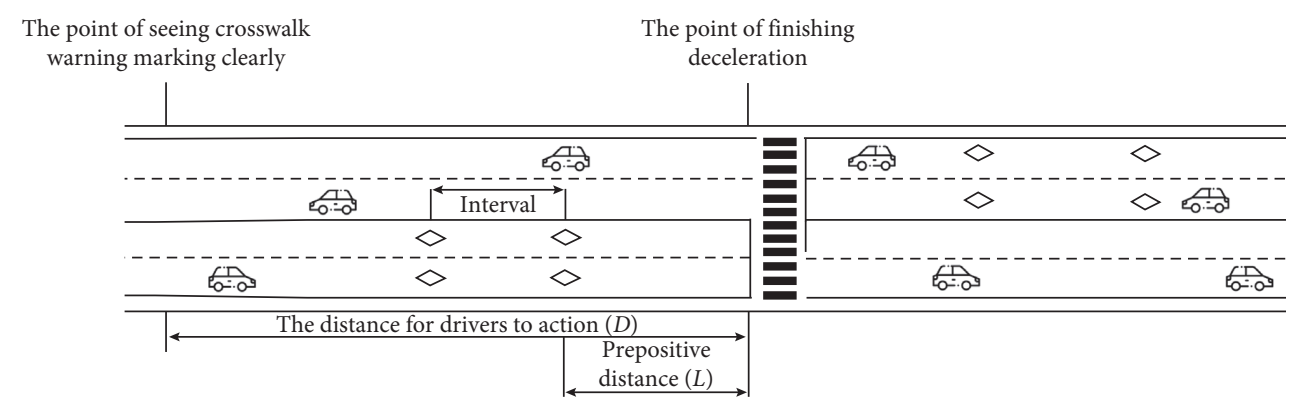

FIGURE 1: The process of recognizing crosswalk warning markings.

According to (1)-(3), the layout interval of the prepositive distance of warning markings under different design speeds is calculated. The calculated value of layout interval is shown in Table 1.

In light of the first group of warning markings that should not be too short and combining with "Road Traffic Signs and Markings" (GB5768-2009) of China, we adjust upper limit of layout interval for the first group of prepositive distance of crosswalk warning markings to $20 \mathrm{~m}$ and adjust the lower limit of layout interval as multiples of 10 . The adjusted value of layout interval is shown in Table 2, which will be used in experiment as boundary condition.

\subsection{Simulations Experiment Design and Procedure}

2.2.1. Simulation Modelling. To simulate driving behaviour and output vehicle's operation data, the simulate experiment was conducted in UC-win/Road version 13.0. UC-win/Road version 13.0 is simulation software, which can establish the actual road alignment and surrounding environment conditions. The software system has a variety of road markings, flowers, trees, and other 2D modelling database; buildings, motor vehicles, pedestrians, and other 3D modelling database; as well as roads, walls, and other materials database. In the UC-win/Road version 13.0 simulation laboratory, the driving simulator is used to simulate the driving scene which is similar to the real situation to obtain the real road similar visual feeling when driving. The experiment scene is displayed on 3-side display screen in $135^{\circ}$ visual field range, at the same time; it is equipped with sound equipment to output the sound heard during driving, which makes the simulation environment more realistic.

This experiment simulation modelling is divided into 4 steps.

Step 1. Calibrate terrain environment: import the terrain information into software, set the project area to China, and edit it, where the terrain elevation needs to be set to more than $0 \mathrm{~m}$; determine the test terrain.

Step 2. Define the road: the two-way four-lane urban roads are selected as the research sections. The lane width is $3.5 \mathrm{~m}$, the width of the crosswalk is $1 \mathrm{~m}$, and the width of the road markings is $0.15 \mathrm{~m}$. The other road plane and section data are default.

Step 3. Set up road ancillary facilities: set up the material, colour, height, and other parameters for the road
TABLE 1: The calculated value of the prepositive distance.

\begin{tabular}{lc}
\hline Design speeds $(\mathrm{km} / \mathrm{h})$ & $L_{1}(\mathrm{~m})$ \\
\hline 30 & $5-42$ \\
40 & $9-85$ \\
50 & $14-119$ \\
\hline
\end{tabular}

TABLE 2: The adjusted value of the prepositive distance.

\begin{tabular}{lc}
\hline Design speeds $(\mathrm{km} / \mathrm{h})$ & $L_{1}(\mathrm{~m})$ \\
\hline 30 & $20-50$ \\
40 & $20-90$ \\
50 & $20-120$ \\
\hline
\end{tabular}

markings, and build the buildings on both sides of the road, with greening and other urban scenes, so that it can truly reflect the actual situation of the city road.

Step 4. Determine the experiment parameters.

(1) Design Speed. The unsignalized crosswalk on the road section is generally set on the main road and the secondary road with the design speed lower than $50 \mathrm{~km} / h$. Therefore, $30 \mathrm{~km} / \mathrm{h}, 40 \mathrm{~km} / \mathrm{h}$, and $50 \mathrm{~km} / \mathrm{h}$ were selected as the design speeds of this experiment.

(2) Parameters of Crosswalk Warning Markings Setting. The layout interval of the prepositive distance of the crosswalk warning markings is in Table 1 . For the design speed of $30 \mathrm{~km} / \mathrm{h}$, the prepositive distance interval of the first group of crosswalk warning markings is $20-50 \mathrm{~m}$, and the increment of the prepositive distance is $10 \mathrm{~m}$. For the design speed of $40 \mathrm{~km} / \mathrm{h}$, and the prepositive distance interval of the first group of crosswalk warning markings is $20-90 \mathrm{~m}$, and the increment of the prepositive distance is $10 \mathrm{~m}$. For the design speed of $50 \mathrm{~km} / \mathrm{h}$, prepositive distance interval of the first group of crosswalk warning markings is $20-120 \mathrm{~m}$, and the increment of the prepositive distance is $10 \mathrm{~m}$. According to the current standard for the size of crosswalk warning markings in China, the shape length, width, and line width of the markings are $3 \mathrm{~m}, 1.5 \mathrm{~m}$, and $0.2 \mathrm{~m}$, respectively. And the markings interval is $20 \mathrm{~m}$.

(3) Roads. In order to provide sufficient driving time for drives to achieve normal driving behaviour in the experiment, it is necessary to reserve enough length road section driving in front of crosswalk. Therefore, when the driving simulation experiment was carried out under the design speed of $30 \mathrm{~km} / \mathrm{h}$, the first crosswalk was set at the location of 
$k 0+500 \mathrm{~m}$, and others were set at a distance of every $500 \mathrm{~m}$. The simulation section consists of 4 crosswalks, with a total length of $2500 \mathrm{~m}$, as shown in Figure 2. For the design speed of $40 \mathrm{~km} / \mathrm{h}$, the simulation section consists of 8 crosswalks, and the crosswalk was set every $500 \mathrm{~m}$, with a total length of $4500 \mathrm{~m}$. For the design speed of $50 \mathrm{~km} / \mathrm{h}$, the simulation section consists of 11 crosswalks, and crosswalk was set every $500 \mathrm{~m}$, with a total length of $6000 \mathrm{~m}$.

(4) Other Parameters. Small vehicles are used as simulation objects to carry out simulation tests during the day when the weather conditions are good. All the simulated roads are free traffic flow of $2300 \mathrm{pcu} / \mathrm{h}$ with pedestrian signs, crosswalk signs, and no speed hump. Figure 3 shows the UC-win/Road version 13.0 simulation modelling.

2.2.2. Simulation Procedure. Forty healthy participants with a $\mathrm{C} 1$ driver's license (quasidriving type in China: car) were selected. Among all the participants, 24 males and 16 females were included, and their driving ages were in the range of $0.5-15$ years (mean 3.24 , variance 0.8 ). The participants were all ensured to have more than eight hours of sleep and were not allowed access to drinking or irritant drugs before the experiment.

To familiarize operating methods of the UC-win/Road version 13.0 driving simulator and the operating performance of the steering wheel, signal, horn, brake, throttle, etc., we conducted a practice for all participants by completing the acceleration and deceleration operation according to the warning information which may occur in the scene before the formal experiment. The driving lane in our experiment is fixed, so the participants will not be affected by other driving behaviours in the road during the driving simulation, which can more directly reflect the speed and the influence of the prepositive distance of crosswalk warning markings on the driver's performance and improve the accuracy of the data. During the experiment, all participants will take the SMI eye tracker; we calibrate the range of crosswalk warning markings as the area of interest, collect the eye movement data, and judge whether the participants pay attention to the crosswalk warning sign before the crosswalk and generate the corresponding driving behaviour, to screen out the effective vehicle operation data.

The prepositive distance starts from the lower limit of each design speed and ends at the upper limit shown in Table 1, and the increment of prepositive distance for each group was $10 \mathrm{~m}$. Therefore, there are three groups of experiments in total as shown in Table 3. The driving experiment starts from the beginning of the simulated road, and one experiment is completed after the road is finished. When one simulation experiment is completed, the eye movement data and vehicle operation date were collected from eye tracker and UC-win/Road version 13.0, respectively. 40 participants took part in all the scenes designed in our experiment.

\subsection{Data Processing}

2.3.1. Data Filters. Both UC-win/Road version 13.0 driving simulator and SMI eye tracker were used in this experiment.
Some time difference will occur when the two pieces of equipment output data. So two kinds of data were compared and analysed to seek data synchronization, and we need to determine the driver's corresponding driving behaviour after having noticed the crosswalk warning markings in the simulated driving experiment and eliminate the free driving time without crosswalk warning sign and the time driver put no attention on crosswalk warning markings as well as abnormal time, so as to intercept the effective experimental time and screen out the effective vehicle operation data such as vehicle speed and deceleration.

2.3.2. Data Reduction. The UC-win/Road version 13.0 simulation software obtains data according to each frame; there are 60 frames per second, and 60 sets of data were obtained. Because the adjacent data time difference is only 41-42 ms, the five consecutive sets of data are basically same data, which cannot reflect the law of data change and cause errors in data processing; besides, a large number of data samples also bring operational difficulties to data analysis. Therefore, we take one set of data every $0.5 \mathrm{~s}$, that is, two sets of data in one second.

\section{Results}

Researches usually evaluate the deceleration effect by analysing the change of the vehicle movement states [14]. To quantitatively evaluate the effect of the crosswalk warning markings, the rate of speed reduction and the times of maximum deceleration were used to evaluate and compare the effectiveness of crosswalk warning markings.

As such, the rate of speed reduction was defined as follows:

$$
\theta=\frac{v_{2}-v_{1}}{v_{1}}
$$

where $v_{1}$ is the speed when vehicle passes the crosswalk warning markings; $v_{2}$ is the speed when vehicle passes the stop lines; and $\theta$ is the relative speed difference.

According to each participant deceleration distribution during their driving under three design speeds, the prepositive distance was recorded when the deceleration turned out biggest, and the times of maximum deceleration of 40 participant at each prepositive distance are counted.

\subsection{Effect of Prepositive Distances on Deceleration (Design} Speed of $30 \mathrm{~km} / \mathrm{h}$ ). The rate of speed reduction at different prepositive distances under a design speed of $30 \mathrm{~km} / \mathrm{h}$ is shown in Figure 4(a); the times of maximum deceleration at different prepositive distances under a design speed of $30 \mathrm{~km} / \mathrm{h}$ are shown in Figure 4(b).

When the design speed is $30 \mathrm{~km} / \mathrm{h}$, we found that all different prepositive distances of crosswalk warning markings have an impact on vehicles' speed reduction. A significance test revealed that the prepositive distance of crosswalk warning markings influences vehicle's speed reduction significantly under $30 \mathrm{~km} / \mathrm{h}(P<0.05)$. When the prepositive distance is $30 \mathrm{~m}$, the speed reduction rate of the 


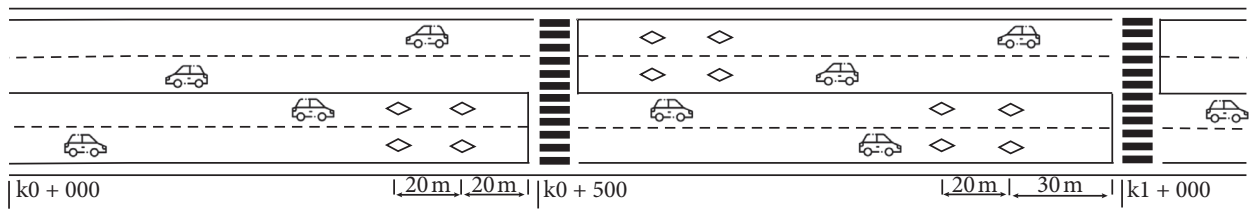

Figure 2: The simulation section $k 0 \mathrm{~m}-k 1+000 \mathrm{~m}$ crosswalk and setting of crosswalk warning markings at $30 \mathrm{~km} / \mathrm{h}$.

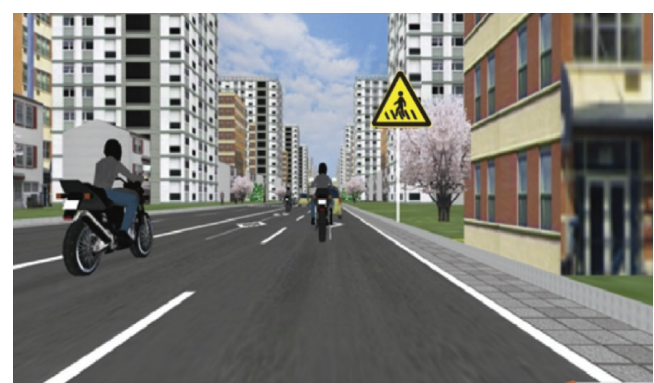

FIgURE 3: The UC-win/Road simulation modelling.

TABLE 3: The experiment groups.

\begin{tabular}{|c|c|c|c|c|c|c|c|c|c|c|c|c|}
\hline \multirow{2}{*}{ The groups of experiment } & \multirow{2}{*}{ Design speeds $(\mathrm{km} / \mathrm{h})$} & \multicolumn{11}{|c|}{ The prepositive distance of the crosswalk warning markings (m) } \\
\hline & & 20 & 30 & 40 & 50 & 60 & 70 & 80 & 90 & 100 & 110 & 120 \\
\hline Exp & 30 & O & O & $\mathrm{O}$ & O & $x$ & $x$ & $\times$ & $x$ & $\times$ & $x$ & $x$ \\
\hline Experiment 2 & 40 & O & 0 & O & $\mathrm{O}$ & O & $\mathrm{O}$ & $\mathrm{O}$ & 0 & $\times$ & $x$ & $\times$ \\
\hline Experiment 3 & 50 & 0 & 0 & 0 & 0 & 0 & 0 & 0 & 0 & 0 & 0 & 0 \\
\hline
\end{tabular}

"O" represents the prepositive distance of the crosswalk warning markings set under the design speed in the experiment, while " $x$ " are not.

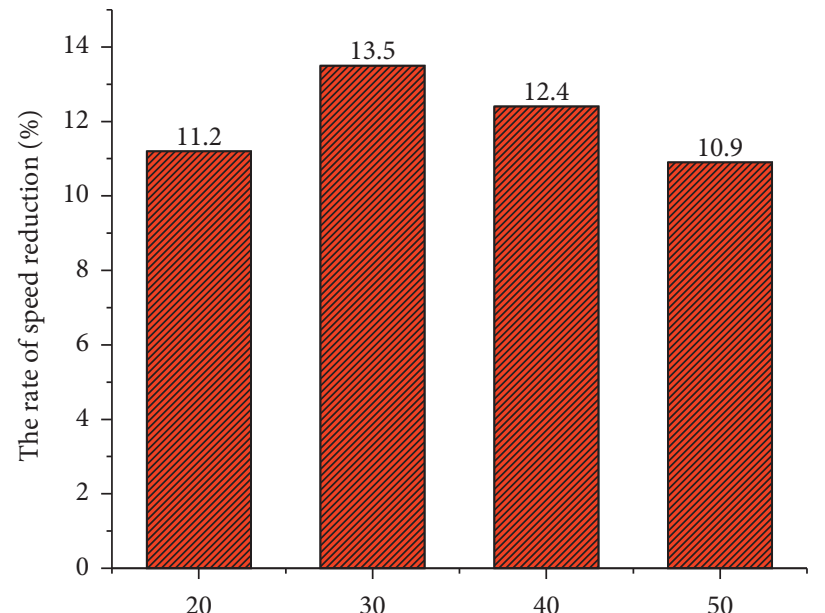

The predistance of the crosswalk warning sign $(\mathrm{m})$

The rate of speed reduction (\%)

(a)

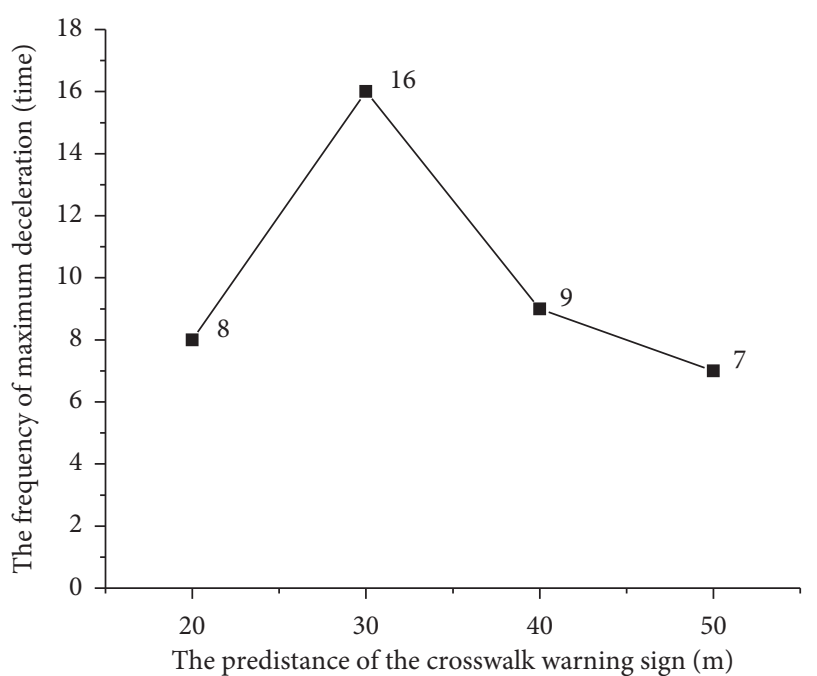

(b)

FIGURE 4: The rate of speed reduction and times of maximum deceleration at a design speed of $30 \mathrm{~km} / \mathrm{h}$. (a) The rate of speed reduction. (b) The frequency of maximum deceleration.

vehicle at crosswalk warning markings and stop line is $13.5 \%$, and the degree of speed reduction is the largest. It can be seen that when the front distance is $30 \mathrm{~m}$, the deceleration effect will be most obvious. At the same time, when the prepositive distance of the crosswalk warning markings is $30 \mathrm{~m}$, we also got the most frequency occurring times of maximum deceleration, as 16 out of 40 participants performed the maximum deceleration behaviour there. It could 
be concluded that when the optimal prepositive distance is $30 \mathrm{~m}$ under the design speed of $30 \mathrm{~km} / \mathrm{h}$, the effect of deceleration is better than others.

\subsection{Effect of Prepositive Distances on Deceleration (Design} Speed of $40 \mathrm{~km} / \mathrm{h}$ ). The rate of speed reduction at different prepositive distances under a design speed of $30 \mathrm{~km} / \mathrm{h}$ is shown in Figure 5(a); the times of maximum deceleration at different prepositive distances under a design speed of $40 \mathrm{~km} / \mathrm{h}$ are shown in Figure 5(b).

As shown in Figure 5, when the design speed is $40 \mathrm{~km} / \mathrm{h}$, we found that all different prepositive distances of crosswalk warning markings have an impact on vehicles' speed reduction. A significance test revealed that the prepositive distance of crosswalk warning markings influences vehicle's speed reduction significantly under $40 \mathrm{~km} / \mathrm{h} \quad(P<0.05)$. When the prepositive distance is $40 \mathrm{~m}$, the rate of speed reduction is the largest, which is $15.2 \%$, indicating that the deceleration effect is most obvious. In terms of deceleration, when the prepositive distance of the crosswalk warning markings is $40 \mathrm{~m}$, the times of maximum deceleration are most; 15 out of 40 participants preformed the maximum deceleration behaviour there. Therefore, for design speed of $40 \mathrm{~km} / \mathrm{h}$, the deceleration effect is most obvious when the prepositive distance of the crosswalk warning markings is $40 \mathrm{~m}$. It could be concluded that when the optimal prepositive distance is $40 \mathrm{~m}$ under the design speed of $40 \mathrm{~km} / \mathrm{h}$, the effect of deceleration is better than others.

\subsection{Effect of Prepositive Distances on Deceleration (Design} Speed of $50 \mathrm{~km} / \mathrm{h}$ ). The rate of speed reduction at different prepositive distances under a design speed of $30 \mathrm{~km} / \mathrm{h}$ is shown in Figure 6(a); the times of maximum deceleration at different prepositive distances under a design speed of $50 \mathrm{~km} / \mathrm{h}$ are shown in Figure 6(b).

As shown in Figure 6, the biggest reduction rate of $17.6 \%$ occurred when the prepositive distance is $60 \mathrm{~m}$. A significance test revealed that the prepositive distance of crosswalk warning markings influences vehicle's speed reduction significantly under $50 \mathrm{~km} / \mathrm{h}(P<0.05)$. In terms of decelerations, the vehicle has the most deceleration times when the prepositive distance of the crosswalk warning markings is $60 \mathrm{~m}$. 12 out of 40 participants preformed maximum deceleration behaviour there. Therefore, for the design speed of $50 \mathrm{~km} / \mathrm{h}$, the deceleration effect is most obvious when the prepositive distance of the crosswalk warning markings is $60 \mathrm{~m}$. It could be concluded that when the optimal prepositive distance is $60 \mathrm{~m}$ under the design speed of $50 \mathrm{~km} / \mathrm{h}$, the effect of deceleration is better than others.

\section{Discussion}

The purpose of this study is to determine the optimal prepositive distance for crosswalk warning markings at different design speeds. If the prepositive distance is too long, the information of crosswalk warning signs will gradually disappear during the process of driving, which will lose the effect of the crosswalk warning markings and sometimes even reduce the driver's trust in it on other sections. While if the prepositive distance is too short, which always means the deceleration distance is too short to stop, then this will lead to safety risks.

On the basis of the experimental results, it could be concluded that when the design speed is $30 \mathrm{~km} / \mathrm{h}, 40 \mathrm{~km} / \mathrm{h}$, and $50 \mathrm{~km} / \mathrm{h}$, the optimal prepositive distance of the first group of crosswalk warning markings is $30 \mathrm{~m}, 40 \mathrm{~m}$, and $60 \mathrm{~m}$, respectively. It shows that the optimal prepositive distances are varied with different design speeds. On one hand, at different vehicle speeds, the driver's visual range can be different, which makes the position different when they are taking a decelerating action before the crosswalk warning markings. On the other hand, in the process of deceleration, vehicles running at higher speed need longer deceleration distance to achieve deceleration or stop. Therefore, under different design speed, the optimal prepositive distances of crosswalk warning markings are different.

The "Road Traffic Signs and Markings" (GB5768-2009) of China stipulates that the prepositive distance of the crosswalk warning markings should be $30-50 \mathrm{~m}$ [10]. Compared with this paper's research results when the design vehicle speed is $30 \mathrm{~km} / \mathrm{h}$ and $40 \mathrm{~km} / \mathrm{h}$, the optimal prepositive distances of $30 \mathrm{~m}$ and $40 \mathrm{~m}$ are within the range specified in standard. When the design speed is $50 \mathrm{~km} / \mathrm{h}$, the optimal prepositive distance is $60 \mathrm{~m}$, which is not in the standard setting range, which is because the difference of vehicle speed is not taken into consideration in the regulations of prepositive distance of crosswalk warning markings. When the speed is high, the distance required in the "Road Traffic Signs and Markings" (GB5768-2009) specification does not meet the need of deceleration. A study of roads in the Netherlands, Spain, and Sweden found that the distance where the driver decided to take action before the crosswalk was about $50 \mathrm{~m}$, and it could be seen that traffic markings with the function of reminding to decelerate at a certain distance before the crosswalk had a corresponding effect on vehicle deceleration; however, according to current study and standard, the difference of the influence of different prepositive distance on the slowing effect is ignored under different design speeds [20]. This paper studied the effectiveness of the layout of the prepositive distance for the crosswalk warning markings under three design speeds, making the crosswalk warning markings more scientific and reasonable.

Similar to many other researches, this paper is also limited by the characteristics of the drivers. The current sample is not so representative of the age distributions in China. In particular, older drivers are substantially underrepresented. In addition, the paper regards the size and interval of the crosswalk warning markings as a certain value, whether different size and interval will produce different results, which is a direction worthy of further study. 


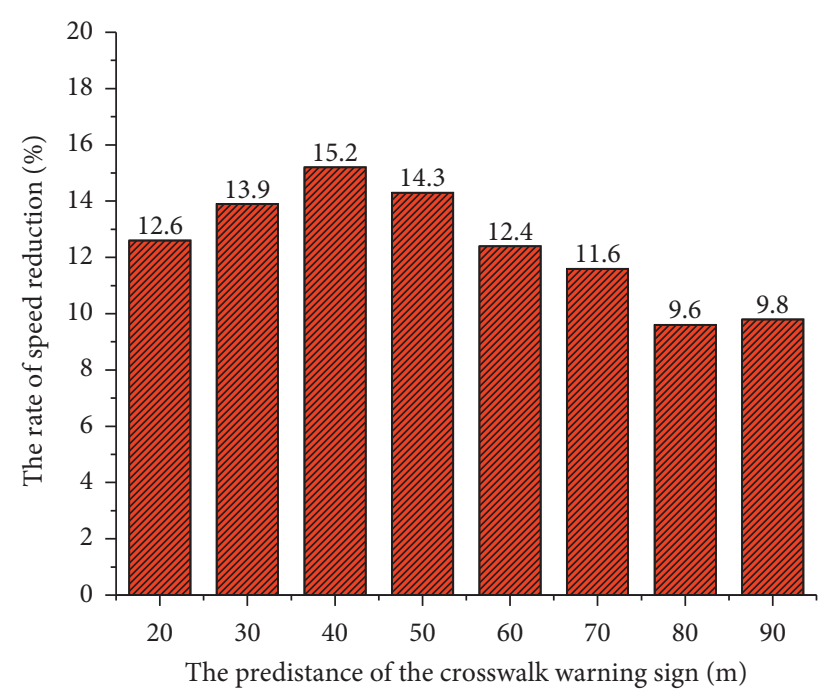

एवि The rate of speed reduction (\%)

(a)

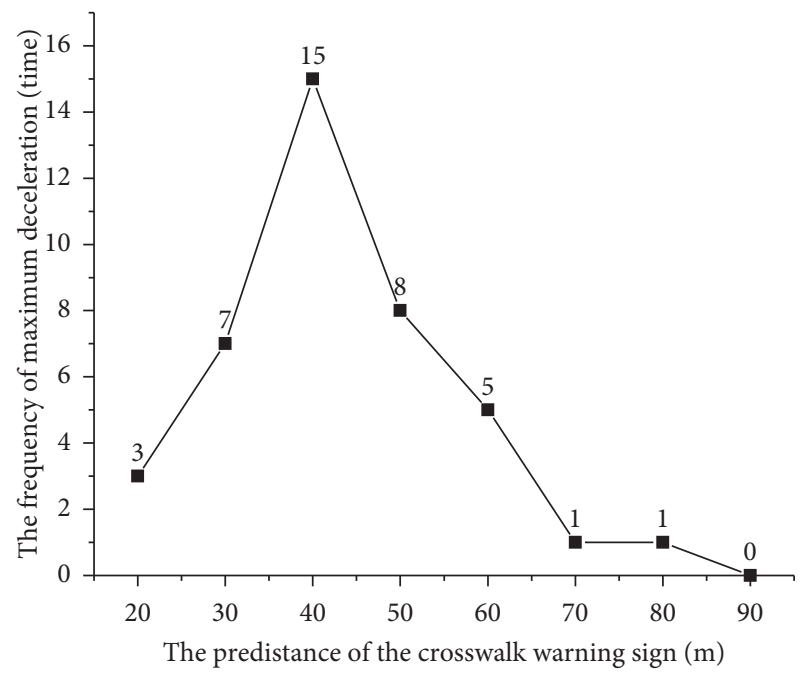

(b)

FIgURE 5: The rate of speed reduction and times of maximum deceleration at a design speed of $40 \mathrm{~km} / \mathrm{h}$. (a) The rate of speed reduction. (b) The frequency of maximum deceleration.

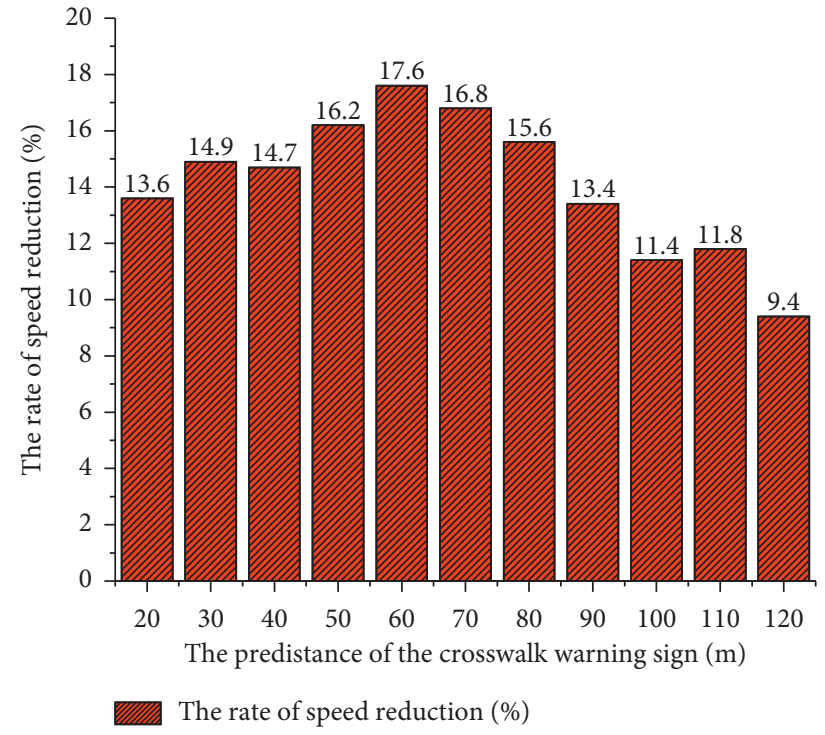

(a)

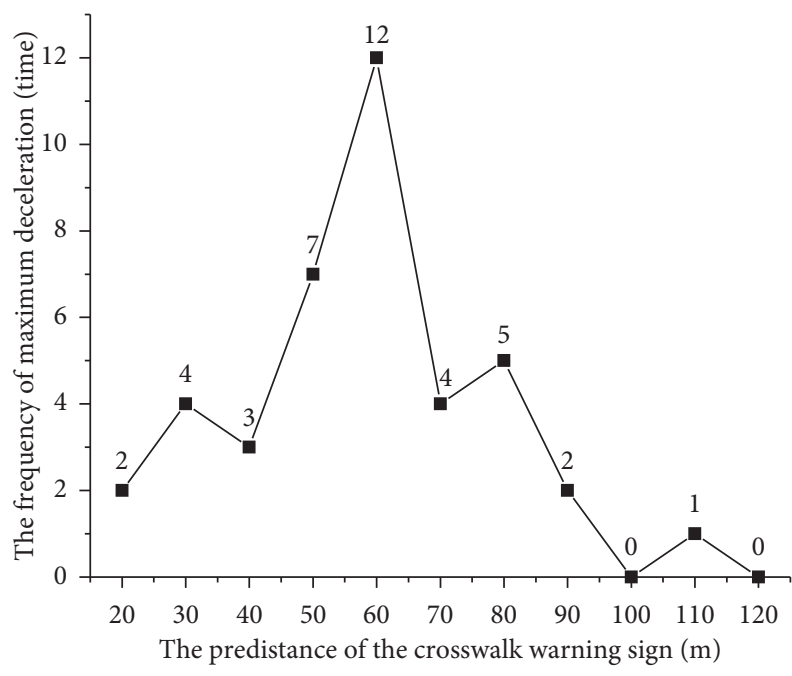

(b)

Figure 6: The rate of speed reduction and times of maximum deceleration at a design speed of $50 \mathrm{~km} / \mathrm{h}$. (a) The rate of speed reduction. (b) The frequency of maximum deceleration.

\section{Conclusion}

Based on mathematical modelling and UC-win/Road version 13.0 driving simulator, this paper proposed the optimal prepositive distance of the crosswalk warning markings under different design speeds for unsignalized road section. The rate of speed reduction and the times of maximum are selected as the evaluation indicators to explain the deceleration effect of crosswalk warning markings. The results show that the distribution of speed reduction rate and maximum deceleration times with different prepositive distance basically present similar regularity under different design speeds. When the design speed is $30 \mathrm{~km} / \mathrm{h}, 40 \mathrm{~km} / \mathrm{h}$, and $50 \mathrm{~km} / \mathrm{h}$, the speed reduction rate and maximum decelerations times all reach the peak when the prepositive distance of the crosswalk warning markings is $30 \mathrm{~m}, 40 \mathrm{~m}$, and $60 \mathrm{~m}$, respectively. It could be concluded that the most reasonable prepositive distance of the crosswalk warning markings, respectively, is $30 \mathrm{~m}, 40 \mathrm{~m}$, and $60 \mathrm{~m}$, when the design speed is $30 \mathrm{~km} / \mathrm{h}, 40 \mathrm{~km} / \mathrm{h}$, and $50 \mathrm{~km} / \mathrm{h}$. The 
conclusion has important reference significance for the specification refinement and revision of the prepositive distance setting of the crosswalk warning markings.

In view of the environment assumed in our experiment, the UC-win/Road version 13.0 driving simulation experiment only considered the traffic conditions of small cars and fixed the lane for drivers, which may influence the action of drivers because of visual shield and so on. Therefore, future research should consider the more simulation conditions to enrich this research.

\section{Data Availability}

The data used to support the findings of this study are available from the corresponding author upon request.

\section{Conflicts of Interest}

The authors declare that there are no conflicts of interest regarding the publication of this paper.

\section{Acknowledgments}

The authors acknowledge the participants for their assistance in the experiments. This work was supported by the Fundamental Research Funds for the Central Universities, CHD (no. 300102210204); the Xi' an Science and Technology Bureau (no. 2019111913RKX003SF007-9); and Shaanxi Provincial Science and Technology Department (no. 2020JM-222).

\section{References}

[1] C. Feliciani, A. Gorrini, and L. Crociani, "Calibration and validation of a simulation model for predicting pedestrian fatalities at unsignalized crosswalks by means of statistical traffic data," Journal of Traffic and Transportation Engineering (English Edition), vol. 7, no. 1, pp. 737-738, 2020.

[2] T. S. Facts, Data, Revised June 2015, US Department of Transportation National Highway Traffic Safety Administration, 1200 New Jersey Avenue SE, Washington, DC, USA, 2013.

[3] D. Lloyd, D. Wilson, and D. Mais, "Reported road casualties great britain: 2014 annual report," 2015.

[4] A. M. Boroujerdian and M. Nemati, "Pedestrian gap acceptance logit modelling in unsignalized crosswalks conflict zone," International Journal of Transportation Engineering, vol. 4, no. 2, pp. 87-96, 2016.

[5] Y. Guo, P. Liu, Q. Liang, and W. Wang, "Effects of parallelogram-shaped pavement markings on vehicle speed and safety of pedestrian crosswalks on urban roads in China," Accident Analysis \& Prevention, vol. 95, pp. 438-447, 2016.

[6] F. Demasi, G. Loprencipe, and L. Moretti, "Road safety analysis of urban roads: case study of an Italian municipality," Safety, vol. 4, no. 4, p. 58, 2018.

[7] T. K. O. Madsen and H. Lahrmann, "Comparison of five bicycle facility designs in signalized intersections using traffic conflict studies," Transportation Research Part F: Traffic Psychology and Behaviour, vol. 46, pp. 438-450, 2017.

[8] P. K. Hughes and B. L. Cole, "What attracts attention when driving?” Ergonomics, vol. 29, no. 3, pp. 377-391, 1986.
[9] J. L. Campbell, Human Factors Guidelines for Road Systems, Transportation Research Board, Washington, DC, USA, 2012.

[10] Ministry of Transport of the People's Republic of China, Road Traffic Signs and Markings GB 5768-2009, China Communications Press, Beijing, China, 2009.

[11] L. T. N. Zealand, Pedestrian Planning and Design Guide, Land Transport New Zealand, Wellington, New Zealand, 2007.

[12] X. Bao, X. Sun, and Y. He, "Application research on freeway speed reduction markings," Transport Standardization $Z$, vol. 2, 2010.

[13] D. Fisher and L. Garay-Vega, "Advance yield markings and drivers' performance in response to multiple-threat scenarios at mid-block crosswalks," Accident Analysis \& Prevention, vol. 44, no. 1, pp. 35-41, 2012.

[14] B.-H. Pan, Y.-J. Yu, S.-Q. Wu, and K.-Q. Yan, "Research on advance distance of guide signs of expressway exits based on UC-win/Road simulation," Journal of Highway and Transportation Research and Development (English Edition), vol. 12, no. 3, pp. 71-79, 2018.

[15] M. Jiang, "A study on prepositive distance model of speed control signs based on visibility and driving characteristics," Highway, vol. 11, pp. 99-104, 2011.

[16] H. Ding, X. Zhao, J. Rong, and J. Ma, “Experimental research on the effectiveness of speed reduction markings based on driving simulation: a case study," Accident Analysis \& Prevention, vol. 60, pp. 211-218, 2013.

[17] Z. Tang, S. Zhao, and J. Wang, "Highway deceleration marking based on driving simulation," in Proceedings of the ICTE 2013: Safety, Speediness, Intelligence, Low-Carbon, Innovation, pp. 521-528, Chengdu, China, October 2013.

[18] D. Vetturi, M. Tiboni, G. Maternini, and M. Bonera, "Use of eye tracking device to evaluate the driver's behaviour and the infrastructures quality in relation to road safety," Transportation Research Procedia, vol. 45, pp. 587-595, 2020.

[19] N. Kudarauskas, "Analysis of emergency braking of a vehicle," Transport, vol. 22, no. 3, pp. 154-159, 2007.

[20] A. Várhelyi and T. Mäkinen, "The effects of in-car speed limiters: field studies," Transportation Research Part C: Emerging Technologies, vol. 9, no. 3, pp. 191-211, 2001. 